Reviews

\title{
Consequences of Cultivar Diffusion. Leonard Plotnicov and Richard Scaglion, editors. Pittsburgh: Ethnology Monographs, no. 17, Department of Anthropology, University of Pittsburgh (1999), xx, 151 pp.
}

\author{
Reviewed by Laurence C. Becker, Department of Geography, University of \\ Nebraska at Kearney.
}

Consequences of Cultivar Diffusion is a collection of ten papers presented at the American Anthropological Association's annual meeting in Philadelphia December 1998. These rapidly published essays together form a rather eclectic volume of refreshingly unpretentious discussions of various food crop diffusion questions. While diffusion is the central theme, the work makes an effort to show how the spread of cultivars - cultivated varieties of domesticated plants - is essentially a part of broader social, political, and economic changes which contribute to making regional and local food systems. For those from undergraduate to researcher fascinated by questions of how "we are what we eat," this collection provides enjoyable reading about the transformations of food, people, and land.

Co-editor Leonard Plotnicov, a cultural anthropologist at the University of Pittsburgh (needed are brief backgrounds on the contributors), introduces the book modestly and accurately noting that the reader should expect no single answers to the numerous questions raised about food transformations (non-food cultivars such as fibers are not considered). The chapters do not attempt to propose theoretical breakthroughs. While this is commendably unaffected, a nagging missed opportunity comes to mind. Rapid cultivar diffusion in recent years has been dramatically changing the quality -and as many assert, the quantity- of foods eaten around the world, as well as the agroecological systems in which they are produced. From the spread of high-yielding crop varieties associated with the Green Revolution in the 1960s to the recent release of genetically engineered (GE) crops, the consequences of cultivar diffusion encompass a broad domain indeed. Instead, Plotnicov uses the need to move beyond materialist explanations of the impact of crop diffusion as an underlying theme. Perhaps overly simple from a political ecology perspective, this approach helps the anthropology-dominated discussion to incorporate the variety of papers in the volume.

The case studies of several world crops and regions can be organized around questions important to historical and contemporary research. While readers from different backgrounds will likely interpret this collection in ways that reflect their interests, four questions are central: (1) What factors cause an introduced crop to be adopted or rejected in a new area? (2) What is the role of physical environments in influencing where crops diffuse? And, conversely, what is the impact of introduced crops on the environment? (3) How are introduced crops incorporated into food and agricultural systems? (4) Has crop diffusion been responsible for subjugating people to market forces, or, as suggested by Plotnicov (pp. xii-xiii) have new crops allowed for the creative response of human agency?

In the chapters, emphasis is on crops first domesticated in the American tropics, but diffusion of Asia-Pacific and African cultivars such as sugar, coffee, sweet potato, rice, and banana also figure prominently. The volume opens with a preface on the distinction between cultivars and cultigens. While this clarifies an element of the book title, the distinction is not crucial to the book's contents because cultigens are not discussed elsewhere, and in most cases the more 
Reviews

familiar "crop" would suffice. Regionally, the ten chapters focus on Papua New Guinea (three chapters), Africa (three), Latin America (two), and Europe (two).

Whether a crop is adopted or rejected in an area to which it has diffused provides a unifying line of inquiry for all of the papers in this volume. Environmental parameters for crop diffusion are fixed largely by the genetic codes of cultivars. Societies, though, incorporate cultivars into local land use systems by modifying environments in ways that reflect the interaction of local and global influences. The U.S. Midwest "Corn Belt," Haiti's eighteenth century sugar cane plantations, Ghana's smallholder cocoa farms, and Poland's landscape of potato fields are each derived from the presence of a diffused crop in particular political ecological conditions. The studies in this book, as Mintz notes (pp. 134-135), are concerned with complex, heterogeneous, and open societies of regional networks where people grow crops, eat, trade agricultural commodities, and give meaning to foods in local cuisines.

David Dodds' chapter builds on Alfred Crosby's The Columbian Exchange (1972), a study of the biological and cultural consequences of the contact between indigenous Americans and Columbus. Dodds' research on the Miskito of eastern Honduras suggests that Asian-origin rice and banana were adopted for socioeconomic reasons (banana as a low labor-input crop and rice initially as an exchangeable good). At the same time, the adoption led to greater forest clearance especially for rice after it had become a preferred local food crop.

The success of cassava diffusion in Africa, due in part to the crop's environmental flexibility, lies at the heart of John Frechione's investigation of cassava toxicity. This chapter provides an excellent review of the literature on cassava toxicity concluding, not so originally, that resulting health problems in Africa may result from cassava technology having been only partially adopted, i.e., the cropping elements but not the processing to remove high levels of cyanogenic glucoside.

Richard Scaglion and Todd Hooe's chapter tries to account for the intensive cultivation and prominent cultural role of sweet potatoes in the central New Guinea highlands. Using mostly linguistic evidence to support the theory of diffusion from Polynesia, they see the sweet potato as allowing for an extension of arable lands since the root crop was better adapted to the degraded soils of the high altitudes.

Beyond the environmental limits to the biological needs of a cultivar and the environmental impact of its adoption, when people come in contact with a crop what determines its local use? James Blaut's (1977) work on diffusion proposed that innovations are pursued only when the socioeconomic conditions for adopting them are present. In this way, food and agricultural systems must have a niche that a new food crop can fill. The success of maize in Africa exemplifies, according to Bruce Roberts' chapter, an American-origin crop that found such a niche and did not replace previously cultivated crops.

In Roberts' ethnographic study of Keiyo smallholder farmers, maize is the most important food crop in different local agroecological zones. Millet and sorghum continue to be grown, less as a risk-aversion practice then for brewing beer. The addition of maize to African cropping systems rather than the neglect of other crops - though there is evidence that maize consumption and production is replacing that of sorghum and millet (Byerlee and Heisey 1997:16-18; Smith et al. 1997:113-114) - has parallels with the experience of rice cultivar diffusion in West Africa. The introduction of Asian rice (Oryza sativa) probably did not have a revolutionary effect on African rice (Oryza glaberrima) systems, just as modern high-yielding varieties have not replaced local cultivars. Paul Richards' (1996:312-313) refers to this practice of incorporating new cultivars into existing cropping systems as 'repertoire enhancement,' a technique that can lead to local cultivars like millet taking on new roles (from staple food to specialized beer ingredient) within an emergent cropping system.

The way that millet appears to become a beer crop in parts of Africa as maize replaces it as a food shows the numerous possible routes a cultivar can take in new lands under the guidance of new hands. The diffused material may not carry with it restrictions on its use developed in the past, as in the case of cassava processing. For example, Terence Hays' notes that young children 


\section{Reviews}

in colonial New Guinea learned to say "tobacco" before "mother" since they were given tobacco as a pacifier. In other chapters, diffused cultivars take on new meanings. The two case studies from Europe are especially illustrative. Susan Tax Freeman describes how American-origin Capsicum became part of the very essence of Hungarian and Spanish cuisines. Her thoughtprovoking essay adds to this book the powerful notion of cultivar diffusion providing the material from which culture is shaped. Foodstuffs acquire meaning and "a place" in the cuisine structure of a region. Stanley Brandes' chapter complements that of Freeman, discussing early European reactions to potatoes and tomatoes. Recognized for their association with other Solanaceae plants, these American-origin cultivars had the mystical powers of the Biblical forbidden fruit: potatoes were blamed for leprosy in France during the 17th and 18th centuries, while both the "apple of the earth" and the "love apple" were reputed to increase sexual desire.

Sugar in Bolivia and Ecuador, "Sweet Interloper" by Mary Weismantel and Sidney Mintz, also raises the question of a cultivar's advance into new territory. Mintz, an emeritus professor of anthropology at Johns Hopkins University who also wrote the conclusion for the book, has written widely about the Caribbean, sugar cane and the forms of its production. The story of sugar diffusion, both as crop and as food, closely follows the history of capitalism. This essay picks up this theme and seeks to separate the plant, its products, and the taste of sweetness. Its strengths are in the political ecology framework for understanding the "old-fashioned" appeal of local foods like Ecuador's flavorful panela in comparison to the modern, sanitized, and tasteless granulated cane sugar. The essay devotes several pages to Buechler and Buechler's (1996) story of a Bolivian market woman in order to suggest that sugar in the form of soft drinks symbolizes modernity and consumerism. Okay, but from her fieldwork in Ecuador in the 1980s, Weismantel recounts her chance meeting with an older woman in a market during which she persuaded the older woman to drink her first Coca-Cola. When the older woman choked on the carbonated drink, it is interpreted as an act of "intended resistance" (pp. 72-73) to powerful, external forces marketing sweetflavored water. This conclusion is itself a bit hard to swallow, since first encounters with carbonation are often very unpleasant and apolitical.

Markets influence production systems everywhere and play a major role in coloring the patterns of crop diffusion. Weismantel and Mintz observe that sugar cane diffused to Ecuador's lowlands where it surpassed highland wool as the national economy's chief commodity. In Paula Brown's essay, coffee production developed in Papua New Guinea as a commercial means for local people to engage with the market, after initially being legally prevented from growing coffee under colonial rule. Who grows coffee today, though, remains an unanswered question. Diffusion of the crop to indigenous farmers was once blocked; are there barriers today that prevent access to coffee growing lands caused by social differentiation that effectively impede diffusion?

Cash cropping histories hover behind several of the case studies of cultivar diffusion in this volume. Maize diffusion in Kenya, for example, followed the path of other cash crops in Africa. As Roberts notes (p.3), the British colonial administration coerced farmers to grow maize. Rocheleau et al. (1995:1043) have shown that quotas for grain exports during the Second World War in a district east of Nairobi, coupled with the promotion of maize in place of sorghum and millet, restructured livelihoods as well as the landscape. Twentieth century maize diffusion comes, then, with reforms promoting commercialization, notably land registration and sedentarization of pastoral peoples. The latter is the topic of Jon Holtzman's contribution, "The Cultivar as Civiliser." While the chapter is less about diffusion of specific cultivars, it shows how British assumptions about pastoralists and colonial development in Kenya were designed to transform pastoralists into modern agriculturalists.

Sidney Mintz's "Final Words" reflect on the contribution of the essays to the understanding of food. Making references to the earlier cultivar diffusion work outside the field of anthropology by such researchers as Nikoli Vavilov and Carl Sauer, Mintz calls for a more interdisciplinary approach to food studies. Writing on food is beginning to respond to the changes in foods, but the kinds of issues addressed in this volume suggest that a new framework is needed. The renewed public interest in the origin of foods and their production, as shown in the growth of community 
Reviews

supported agriculture and further stimulated by reaction against the market domination of a few corporations, as well as environmental and health concerns raised by GE crops, shows a need for new and more interdisciplinary efforts.

\section{References Cited:}

Blaut, James.

1977. Two Views of Diffusion. Annals of the Association of American Geographers 67(3):343-349.

Buechler, Hans, and Judith-Maria Buechler.

1996. The World of Sofia Velasquez: The Autobiography of a Bolivian Market Vendor. New York: Columbia University Press.

Byerlee, Derek, and Paul Heisey.

1997. Evolution of the African Maize Economy. In Derek Byerlee and Carl Eicher, eds., Africa's Emerging Maize Revolution. Boulder: Lynne Riener, pp. 9-22.

Crosby, Alfred.

1972. The Columbian Exchange: Biological and Cultural Consequences of 1492. Westport, Connecticut: Greenwood.

Richards, Paul.

1996. Agrarian Creolization: The Ethnobiology, History, Culture and Politics of West African Rice. In Roy Ellen and Katsuyoshi Fukui, eds., Redefining Nature: Ecology, Culture and Domestication. Oxford: Berg.

Rocheleau, Diane; Steinberg, Philip; Benjamin, Patricia.

1995. Environment, Development, Crisis, and Crusade: Ukambani, Kenya, 1890-1990. World Development 23(6):1037-1051.

Smith, Joyotee; Weber, Georg; Manyong, M.V.; Fakorede, M.A.B.

1997. Fostering Sustainable Increases in Maize Productivity in Nigeria. In Derek Byerlee and Carl Eicher, eds., Africa's Emerging Maize Revolution. Boulder: Lynne Riener, pp. 107-124.

\section{Requiem for Nature, by John Terborgh (1999) Washington, DC: Island Press. xii, 234 pp.}

\section{Reviewed by Kathryn L. Michaud, Clark University, Worcester, MA.}

With tropical deforestation continuing at an alarming rate, work by authors like John Terborgh is needed now more than ever. And general trends in globalization of regional economies and foreign direct investment, by which corporations from industrialized countries often establish plants in developing countries (Encarnation 1995), further heightens the need for specialists to engage the public on the issue of tropical deforestation and habitat destruction.

The disturbance of tropical forest ecosystems is troublesome, of course, for several 